\title{
Chapter 11 \\ Educating Cultural Literacy with Open \\ Educational Resources: Opportunities \\ and Obstacles of Digital Teacher \\ Collaborations
}

\author{
Elisabeth Mayweg-Paus and Maria Zimmermann
}

In this chapter, we set the context for how teachers can use the CLLP (see Chapter 1) and its resources sustainably by introducing why it is important for teachers to engage in long-term collaboration to implement the core aims and themes of DIALLS in a meaningful way. In the following chapter, we will introduce research on the opportunities and obstacles of online collaboration among teachers. Considering that the goals of DIALLS deal with issues of living together, social responsibility, and sustainable development, we will emphasize how effective online collaboration not only among students but also among teachers can help make DIALLS have a long-lasting impact that shapes the educational future of Europe. Thus, we will emphasize how to promote a long-lasting community of practice for DIALLS teachers and how this community may enable them to become professional DIALLS teachers.

The DIALLS project provides open educational resources (OER) (i.e., the project website's educational materials are open access for teachers) that can be used by teachers who are willing to integrate the DIALLS learning program into their teaching. While the open access status of educational resources per se is likely to increase teachers' willingness to use them, teachers still emphasize the need for technical and pedagogical support in using these OERs (Baas et al. 2019). So, how can we ensure that future teachers feel comfortable and competent in using the DIALLS resources, especially because professional trainings for DIALLS educators will be limited in the future (see Chapter 10 for a description of the professional trainings that were offered during the second year of the DIALLS project)? Here, we encourage teachers to support each other when using the DIALLS resources, as collaborations among teachers who use DIALLS may support each other's self-determined professional development. With respect to achieving the intended benefits of OERs,

E. Mayweg-Paus $\cdot$ M. Zimmermann ( $₫)$

Faculty of Humanities and Social Sciences, Department of Education Studies, Digital Knowledge Management, Humboldt University of Berlin, Berlin, Germany

e-mail: maria.zimmermann@hu-berlin.de 
UNESCO considers that OERs need to be embedded "by information and communication technologies, for consultation, use and adaptation by a community of users for non-commercial purposes" (UNESCO 2002, 24) (e.g., within communities in organizational or academic contexts). Similarly, teaching per se is a skill that is best developed within a supportive network (Cox 2004). In order to understand more precisely why such communities could be beneficial for helping teachers educate children on cultural literacy, we would like to describe the patterns of an online community of practice for DIALLS.

\subsection{Communities of Practice-a Teacher Community of Practice for DIALLS}

Considerable research states that learning is highly social (Bandura 1977) and, according to social capital approaches (Lin 1999), an individual's willingness to voluntarily help, share, and collaborate in groups can foster prosocial actions toward achieving shared objectives — such as achieving learning goals of a common learning program. Lave and Wenger (1991) were the first to coin the term community of practice $(\mathrm{CoP})$, which describes how professional development can occur through participating in a group of practitioners that pool a broad base of knowledge and perform practices centered around three structural key features: domain, community, and practice (Wenger 1998). For example, for a CoP that aims to achieve the learning goals of DIALLS, the domain might be established as a result of teachers' shared interest in using the Cultural Literacy Learning Programme (CLLP) to foster their students' cultural literacy by instructing them to discuss about cultural (sub-)themes (e.g., tolerance, cultural heritage, climate change, solidarity). Furthermore, the feeling of belonging to a community would be the essential feature to "make mutual engagement possible" (Wenger 1998, 74). Wenger (2002) further stresses that, although members of a CoP would need to connect regularly, they wouldn't necessarily have to meet every day nor in person, as interactions can be promoted by the use of technologies which would then allow for online discussions and reflection. This is of particular importance, as teachers from all over Europe shall be able to use the CLLP. Thus, a CoP that is connected online would help to connect teachers remotely from several cities and even countries. However, to overcome language barriers of participating teachers who may not speak the same language, technical support by, for instance, automatic translation software would be needed.

However, the traditional understanding of a CoP may be not completely comparable to existing online learning communities, since CoPs often only come together in a purpose-oriented and unique way. Thus, to overcome a situation where members are only "searching for and sharing decontextualized ideas, resources, information, and knowledge without reference to authentic classroom learning settings" (Trust 2015,78 ), especially in an online learning community, the sense of being part of a community needs to be strengthened. 
Moreover, in a CoP for DIALLS, teachers would not only use the provided resources but would additionally develop and share their experiences with using the resources, including their successes and failures. Thus, the members of a DIALLS CoP would share practices and develop "a shared repertoire of resources: experiences, stories, tools, ways of addressing recurring problems" (Wenger 2012, 2). In this sense, they may share experiences about how students reacted to sensitive themes (e.g., homosexuality or migration) and may collaboratively discuss how to handle situations in which they may have experienced uncertainty in how to react toward students' behaviors.

By considering the time that is needed to build a meaningful $\mathrm{CoP}$ and the challenges of directly assessing such a CoP's success, the value creation framework (VCF) describes five dynamic interrelated cycles of value creation (Wenger et al. 2011). Each of these cycles is assumed to produce certain indicators that allow for monitoring a CoP's success over time. The framework is particularly useful for describing the value created for individual members of a CoP regarding the CoP's personal impacts on teachers themselves, its impacts on their teaching, and also its impacts on the school environment (McKellar et al. 2014). The first cycle refers to the immediate value of a DIALLS CoP by emphasizing the immediate value of teachers' activities and interactions (e.g., one teacher may get help from another on how to deal with a challenging teaching situation). The second cycle would rely on the potential value of increasing knowledge capital (e.g., a teacher may improve skills in perspective taking or gain knowledge on how to teach DIALLS lessons). The third cycle expands these values to applied value, which refers to any changes in teaching practices (e.g., a teacher reuses and adapts DIALLS lesson plans to different classes). In the fourth cycle, realized value refers to any improvement in performance (e.g., a teacher changes practices but also reflects on how the application of her skills affects the students' achievement of cultural literacy). In the last cycle, a CoP's reframing value may be observed whenever the teachers in a DIALLS CoP redefine the success of the CoP (e.g., when teachers redefine what the CoP could be helpful for in the future).

Besides these intended values of a DIALLS CoP, the exchange of experiencesconsidered an immediate value - may be one of the main motivators for teachers to engage in a CoP (Macià and García 2016). Teachers' actual reasons for engaging in online CoPs in particular are manifold and include (1) exchanging knowledge and materials, (2) developing common projects and didactical methods, (3) sharing and experiencing psychological support after emotional exchanges, and (4) overcoming loneliness and experiencing a sense of community (De Laat and Schreurs 2013; Hur and Brush 2009; Lantz-Andersson et al. 2018).

In addition, the observed benefits and values of online CoPs may go beyond teachers' expectations and motivations for joining a CoP, as research indicates that pre-service teachers who participated in online CoPs had more pronounced selfefficacy beliefs regarding their teaching (Inel Ekici 2018). Furthermore, online CoPs 
were found to help teachers in developing self-efficacy regarding the use of technology and collaborating with other colleagues on the development of interclassrelated curriculum units (Vavasseur and MacGregor 2008); the latter could be particularly important for DIALLS when students engage in dialogic exchange about cultural themes in other classes. In such instances, it is important for teachers to collaborate with the teacher of the other class so that both classes discuss the topic in a meaningful way. Furthermore, with respect to the benefits of informal teacher learning settings, a meta-analysis by Kyndt et al. (2016) reviewed 74 journal articles and found that engaging in such informal activities, such as being part of an informal learning community, led to improved subject knowledge, enhanced pedagogical skills and knowledge, as well as changed professional attitudes and identities.

Importantly, whether a $\mathrm{CoP}$ is organized formally or informally does result in different opportunities and obstacles that need to be considered in terms of the success of the CoP (Lantz-Andersson et al. 2018). While the learning and teaching materials from DIALLS have been created according to European educational policies as well as national curricula, the use of DIALLS resources is not a mandatory part of any European countries' curricula. Thus, teachers and school principals can voluntarily decide whether they want to use the resources to educate their students' cultural literacies with argumentation and dialogue. Accordingly, teachers' participation in a DIALLS CoP would also be voluntary, which again emphasizes not only the importance of a CoP but also the CoP's informal character, since a non-structurally anchored use of DIALLS materials makes it unlikely that a learning community would be formally organized by schools. In contrast to formally developed CoPs, the teacher members of an informally developed DIALLS CoP would not necessarily collaborate with colleagues from the same school but instead would contribute to a community with members from all over Europe.

\subsubsection{Opportunities and Obstacles of a Community of Practice for DIALLS}

Harnessing the perceived values of online communities of practice across educational contexts requires well-designed conditions and settings to achieve a sustainable level of functionality, communality, collaboration and knowledge sharing, which would allow the CoP to overcome challenges often observed in online teacher communities: For instance, informally developed online teacher communities often consist of many passive participants (i.e., lurkers) who observe rather than actively engage (LantzAndersson et al. 2018). While passively reading others' contributions in a CoP may increase an individual member's knowledge, participating only passively inhibits rich perspective taking among all members and, thus, prevents the full potential of a CoP from developing (Cuthell 2005). Similarly, Stuckey and Smith (2004) highlight the importance of active participation within a $\mathrm{CoP}$ and advocate for some 
members to become "leadership members"; these members not only participate actively themselves but also keep other members involved in the community.

In contrast to CoPs that have few active participants, an online teacher CoP, especially one that is informally developed, may overcome this issue because it may serve as a means of professional as well as emotional support, and members may feel encouraged to take risks and discuss successes as well as failures and challenges without feeling like those struggles are being viewed by one's day-to-day colleagues (Lantz-Andersson et al. 2018; Williams 2006). In this sense, personal distance in online communities may overcome members' hesitation to share problems with inhouse colleagues (Hur and Brush 2009). Accordingly, the exchange of experiences and support within an online CoP might be particularly important for teachers who are aiming to use the DIALLS resources because the teaching resources are not embedded into formal curricula; embedding them formally would have guaranteed that every colleague in one's school would use them and that teachers would have to share experiences with face-to-face contacts. Instead, a DIALLS CoP can avoid this drawback and offer a community where members exchange their experiences regarding the subject-specific use of resources to teach cultural literacy.

In sum, research has identified specific elements that are perceived as crucial for the success of online CoPs (Apostolos and Alivisos 2010; Lantz-Andersson et al. 2018; Kastens and Manduca 2017; Kraut and Resnick 2011; Stuckey 2004; Vavasseur and MacGregor 2008). For instance, Apostolos and Alivisos (2010) reviewed 38 journal articles on CoPs and identified an extended list of potentially relevant characteristics for an online-mediated CoP: (1) structural characteristics (e.g., active members of a CoP or the quality of collaboration and interactivity actions), (2) motivators (e.g., peer relations/social networking and reuse of resources), (3) success factors (e.g., the acceptance of communication rules or common understanding), and (4) barriers (e.g., lack of communication norms and tools, asynchronous communication, or a high competitiveness). In this context, Kastens and Manduca (2017) highlighted the relevance of similar aspects when referring to an actual CoP for GeoScience education. Additionally, they emphasize the importance of time and dynamic development to increase the benefits intended for individuals or for the collective.

With an integrative perspective, Stuckey (2004) outlined six common frameworks of CoPs and derived common guidelines and principles that are considered relevant to develop, implement, and sustain an online-mediated CoP. In Table 11.1, we show these guidelines as adapted to the development, implementation, and sustaining of a DIALLS CoP (for more information on the frameworks, see Stuckey 2004). Table 11.1 summarizes aspects related to the common ties (the domain) of the CoP, the members of the CoP, the members' social interaction, and areas within the CoP that are considered relevant for the success of the DIALLS CoP.

What is particularly important in most CoP research, however, is how to encourage effective social interaction in the form of effective collaboration and communication among the CoP members (Lantz-Andersson et al. 2018; Vavasseur and MacGregor 2008). In general, research has indicated that effective online-mediated communication in CoPs is positively correlated with feelings of belonging, trust, support, and 


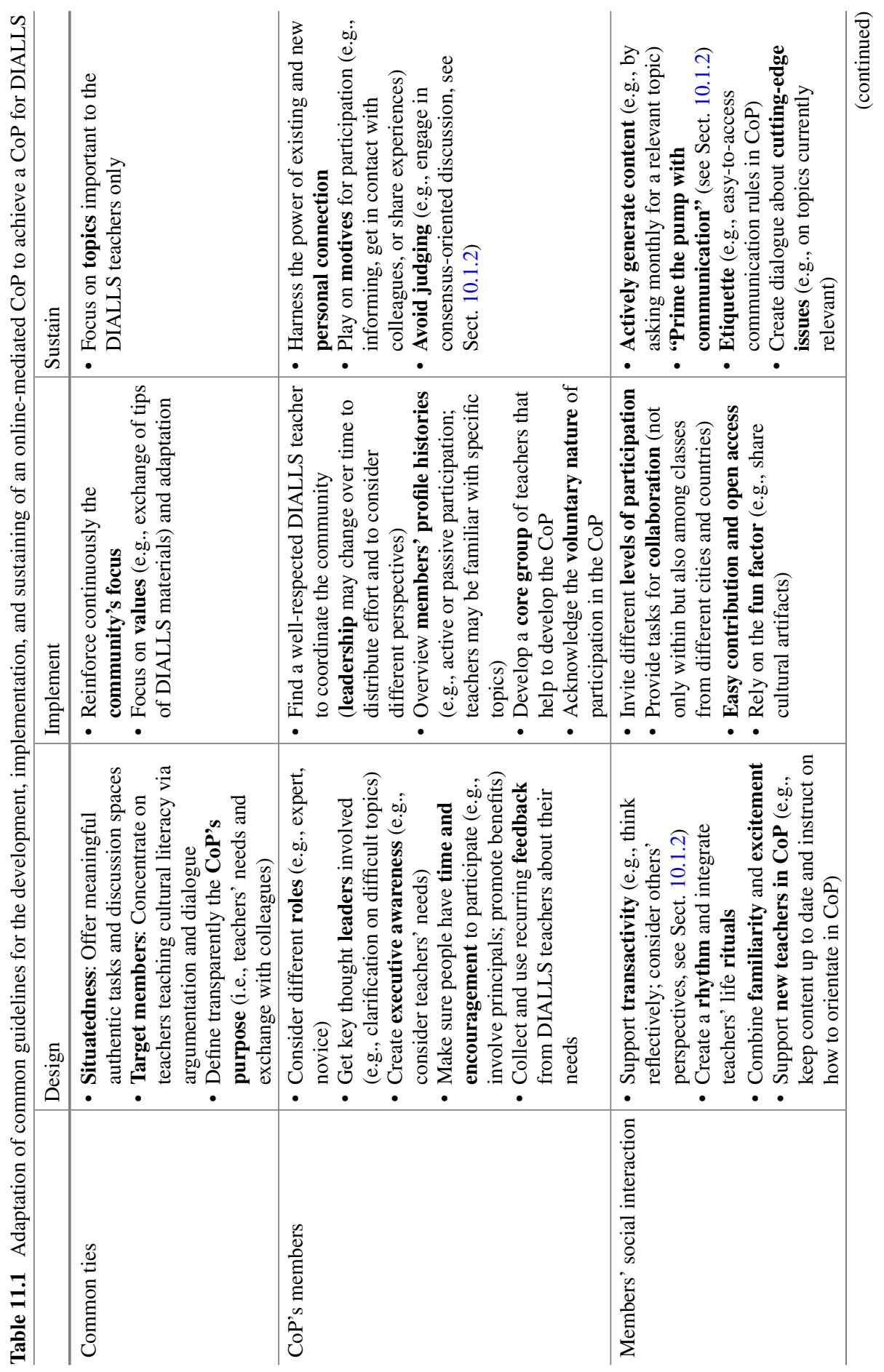




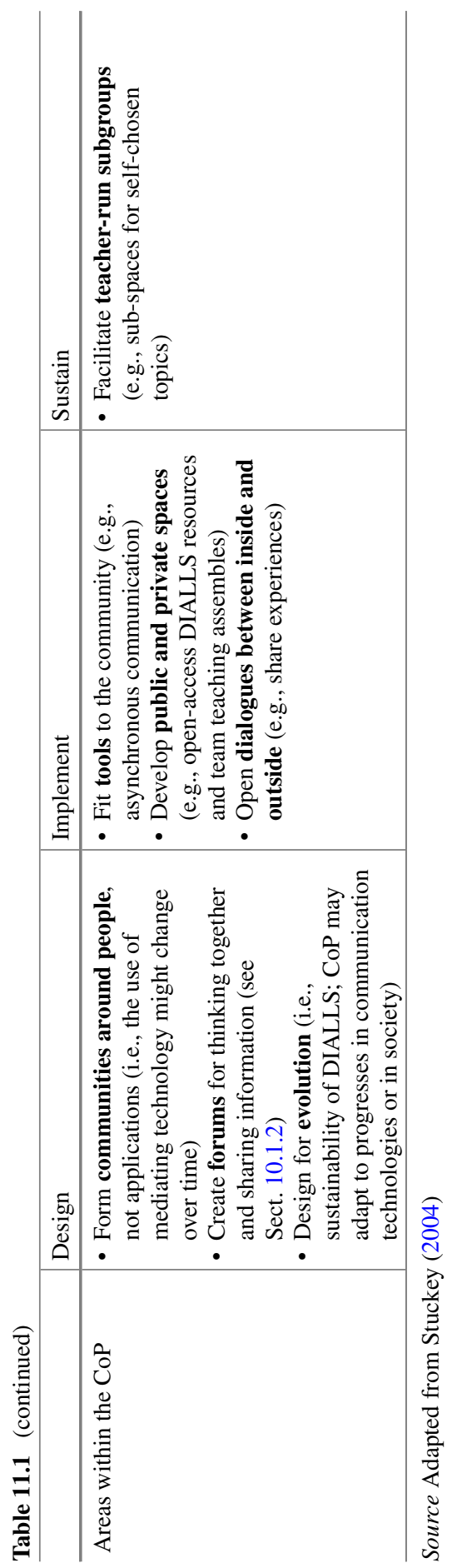


community (Williams 2006). As a result, the more effective the discussions, sharing, and support are, the more the CoP contributes to teachers' professional development (Tseng and Kuo 2014). In this sense, teachers that are part of a CoP for DIALLS need to be engaged in reflective and collaborative conversations about the efficacy and the meaningful use of the CLLP. While collaborating and communicating effectively in an online-mediated $\mathrm{CoP}$ offers various opportunities, there are many obstacles as well.

\subsubsection{Opportunities and Obstacles of Collaborative Argumentation Among Teachers Online}

Drawing on social constructivist theories, collaborative learning approaches in education are based on the idea that knowledge and skills are co-constructed through social interaction (Knowles et al. 1998). Extending this to the form of social interaction in online CoP approaches, a key learning activity in an online CoP that could promote outcomes such as critical reflection, problem-solving skills, and learning about a particular topic might be computer-mediated collaborative learning (Chinn and Clark 2013; Namdar 2017; Noroozi et al. 2012). In these learning environments "learners [namely, teachers who are learning in the context of their professional development] communicate with each other via text-based [...] discussion boards [and] are supposed to engage in argumentative discourse with the goal to acquire knowledge" (Weinberger and Fischer 2006, 71). In this sense, collaborative learning is more than merely working together. Collaboration is considered a learning process with "co-elaboration of conceptual understanding and knowledge" (e.g., Baker 2015, 4).

Thus, collaborative learning involves those communicative activities that are also intended in the DIALLS learning program and that should be encouraged by DIALLS teachers when involving their students in dialogues about cultural themes. These communicative activities are geared toward explaining and understanding ideas, representing knowledge and concepts, gaining multiple perspectives from learning partners, as well as arguing collaboratively (Asterhan and Schwarz 2016; Chinn and Clark 2013). The latter, collaborative argumentation, is also considered important for teachers who take part in the DIALLS CoP (e.g., Apostolos and Alivisos 2010; Namdar 2017). Teachers' collaborative argumentation would occur when teachers exchange statements and questions, make claims about their teaching perspectives and approaches, support these claims with arguments, and question other arguments critically.

Although, collaborative argumentation is important, it should not replace teachers' emotional exchanges. Rather, collaborative argumentation has the potential to overcome superficial consensus-building in discussions. For instance, when discussing 
pedagogical strategies, teachers may take part in a discussion by more deeply considering each other's perspective or critically questioning their own arguments and adapt their pedagogical strategies accordingly.

Further, as collaborative argumentation can result in agreement or disagreement among teachers, it must be distinguished from any competitive assertion of one's own opinion (Chinn and Clark 2013). While the aim of argumentative discourse can either be to persuade or to reach a consensus, a consensus-oriented type of discourse may increase the benefits of collaborative argumentation while opposing any barriers due to competition (Apostolos and Alivisos 2010) because the teachers in a CoP would be able to interactively use arguments originally introduced by other members and more critically challenge their own arguments (Felton et al. 2015). In particular, teachers may substantially benefit from collaborative argumentation because it can be used to successfully integrate multiple perspectives (Veerman et al. 2002), it can promote interactions among teachers in a transactive way, such as challenging the partner's knowledge and arguments (Mayweg-Paus et al. 2016; Vogel et al. 2016), and it can involve high-quality argumentation strategies such as critical questioning of the arguments (Mayweg-Paus et al. 2016). In this sense, collaboration among teachers per se describes an interactive process that enables teachers with diverse expertise to work together as equals and engage in reasoned decision-making toward pedagogical goals. Hence, a consensus-oriented discourse would support the aim of a DIALLS CoP to provide collegial support to coequal members.

However, because it is not natural for humans to critically question or to hone skills related to arguing collaboratively, teachers would benefit from instructional support on how to argue and critically reason when engaging in consensus-oriented discourse (Mayweg-Paus et al. 2016; Noroozi et al. 2012). Accordingly, any uninstructed communication among teachers in online CoPs tends to be rather superficial, seldom leads to in-depth discussions about the corresponding instructional or pedagogical issues, and can lack reflection as well as the critical sharing of practices (Lantz-Andersson et al. 2018). This is perhaps unsurprising though, since teachers rarely connect their pedagogical and conceptual knowledge with their own and other teachers' teaching practices in a transactive way (Hawkes and Romiszowski 2001). Nonetheless, if teachers could meaningfully reflect on existing practices that have been shared by the other teachers, this reflection could help them critically examine the practices and identify whether they could synthesize a different perspective into their own teaching, thus supporting the development of their own teaching practices (Danielowich 2012).

In contrast to synchronous online communication among teachers (i.e., at the same time without delay), asynchronous forms of communication (i.e., at different times, which can lead to a delay in transactive responses) may inhibit the immediate exchange and interactivity of communication and, hence, may make teachers less willing to exchange personal experiences and situations (Loving et al. 2007; LantzAndersson et al. 2018). However, as the interactions in an online-mediated CoP for DIALLS hinge on teachers' critical reflection, as this may help teachers collaboratively discuss the DIALLS topics in a consensus-oriented way, the process of writing a non-immediate response may stimulate forms of reflection and self-analysis that 
would not be evident in face-to-face meetings (Unwin 2015). For example, Choi and Morrison (2014) found that compared to discussions had by teachers who met in person, asynchronous online discussions by those same teachers were more reflective and featured a more diverse range of perspectives.

To sum up, patterns of communication in a CoP can have several functions, all of which are relevant in the context of professionalization. For example, while exchanging practical hints and tips or sharing one's experiences may directly serve the purposes of emotional relief or obtaining support, these forms of communication do not necessarily require deeper critical reflection and elaboration through collaborative argumentation. On the other hand, understanding one's own teaching practices and another person's perspective requires teachers to critically question arguments and to transactively engage in discussions that may allow for deeper learning and may apply to other educational situations. Accordingly, encouraging teachers to engage in collaborative argumentation in a CoP will help promote long-lasting professional development of their teaching skills.

\subsection{Implications Gained from the Insights of an Emerging Community of Practice for DIALLS}

In this final section, we give examples on what the spaces for collaboration among teachers in DIALLS look like. In this vein, we offer a comprehensive picture of what the DIALLS teacher could actually learn and value from a DIALLS CoP and describe how their collaborative argumentation can help to achieve a DIALLS CoP and, thereby, to sustain the impact of DIALLS.

During the DIALLS project, an online discussion forum was implemented that gave the teachers a space to collaboratively work together without time or local restrictions. As one of the main goals in DIALLS is to promote students' dialogue and argumentation so they can better consider other perspectives on cultural themes, the teachers involved in a DIALLS CoP also need to collaborate with colleagues and, hence, may experience similar opportunities and obstacles that their students may experience during a DIALLS lesson. Accordingly, encouraging teachers to work collaboratively and to express their opinions while listening to and respecting the opinions of their colleagues may, in turn, help improve their ability to teach students how to argue. This forum also offered teachers who taught DIALLS the opportunity to find and collaborate with self-reliant colleagues who also taught DIALLS and who might be interested in bringing their classes together to conduct the DIALLS lessons that were particularly designed to have students from different cities or countries exchange experiences. In the following we will provide a selection of teachers' comments representing their perspectives and needs. Based on this, we will highlight the central requirements of the DIALLS CoP and how they were addressed by the 
implementation of design principles (see Table 11.1). Finally, we will draw conclusions on the role of a long-lasting CoP for sustaining the impact of DIALLS in the future.

From the German teachers' feedback ( $N=16$; those who took part during the implementation phase) on the usefulness of online discussion forums, the teachers underlined the potential such forums in the context of DIALLS. Regarding the common ties of the DIALLS CoP, one teacher expected that "if everyone contributes their plans and applications [of the DIALLS materials], it can help [future] teachers". This exemplary expectation is reflected in the DIALLS CoP's purpose and its value, as members' exchange of materials could be a long-lasting outcome of their collaboration. Similarly, the teachers further emphasized the need to exchange with colleagues, receive tips from them, to discuss how they adapted lesson plans toward the specific needs of their students, and the importance of exchanging ideas about "how to deal with challenges during lessons". All the teachers expressed their future willingness to contribute to the CoP. Having contributions to the CoP from both expert teachers who are familiar with teaching DIALLS and novice teachers who are looking for some guidance can help keep the CoP going and will likely infuse the CoP with diverse values. With regard to the members of the DIALLS CoP, this means that novice and expert DIALLS teachers have been invited to take part in the CoP. Novice DIALLS teachers in particular could benefit from the expertise of those who are familiar with DIALLS. While such novice teachers may benefit from posts by expert teachers and may be more passively involved in information consuming to increase their personal knowledges and skills, the expert teachers could take on the role of vocationalists who share tips and expertise and keep an eye on the needs of the CoP itself (Prestridge 2019). In this sense, one teacher highlighted that expert teachers "could act as moderators for further professional reflections on the use of DIALLS materials". Accordingly, the experts could occasionally take on a moderating role and may stimulate the manner of social interaction between the members, for instance, by supporting new teachers with instructions on how to find certain topics within the CoP.

Finally, here we offer examples of topics that emerged in the DIALLS online discussion forum and describe how they relate to the intended values of a DIALLS CoP. In line with the value creation framework (Wenger et al. 2011) described above, the space for discussion and exchange in the DIALLS online discussion forum allowed teachers to harness the immediate, potential, applied, realized, and reframing values and, thus, can be considered helpful for achieving a long-lasting CoP for DIALLS. First, we highlight the forum topic "Delights and frustration: My experiences with the DIALLS learning program" wherein teachers exchanged their personal experiences; this exchange many have provided the immediate value of sharing and receiving support from colleagues (e.g., about any challenging teaching situation). Within the forum topic entitled "What I personally have learned from DIALLS", teachers could, for instance, discuss whether any DIALLS teaching materials influenced their own perspectives on European values. Such discussions may relate to the applied and realized value of the DIALLS CoP, as teachers here reflected not only on how they taught a specific DIALLS lesson but also on how this teaching 
impacted them personally. Other forum topics addressed the reframing values of the DIALLS CoP (e.g., "Help to create our community!", in which teachers could express their wishes for other forum topics or the $\mathrm{CoP}$ itself). In addition to addressing teachers' needs and, hence, continuously assessing what they expected from the CoP, the form also offered a netiquette on how to communicate meaningfully. Displaying such forms of communication rules (e.g., instructing the teachers to ask each other questions, encourage them to read others' posts in order to check whether something similar was posted before) are considered important not only for reducing redundancy but also for encouraging teachers to actively take part in the CoP and to react transactively to what their colleagues contributed. Furthermore, teachers could also easily view the CoP's own values, which helped increase teachers' awareness about the intended benefits and aims of the online discussion forum and the DIALLS CoP. Importantly, sustaining the CoP and, thus, the impact of the entire DIALLS project, relies heavily on having an actively ongoing community of practice (e.g., The California Center for College and Career 2013).

In this sense, continuously promoting the values of the DIALLS CoP as well as providing pleasant and easy-to-access spaces for meaningful collaboration among teachers that allow members to learn and redefine their own $\mathrm{CoP}$ in a self-determined way will help sustain the impact of DIALLS in the future. DIALLS addresses highly relevant topics for education and for our society. Establishing and maintaining a DIALLS CoP will make a meaningful contribution to keep DIALLS practices alive, as it flexibly allows teachers to react to the demands of this ongoing changing society and to adapt DIALLS to it.

\section{References}

Apostolos, K., and S. Alivisos. 2010. Internet-mediated communities of practice (IMCoPs): A meta-analysis of critical elements. International Conference on Intelligent Networking and Collaborative Systems 2010: 1-7. https://doi.org/10.1109/INCOS.2010.23.

Asterhan, C.S.C., and B.B. Schwarz. 2016. Argumentation for learning: Well-trodden paths and unexplored territories. Educational Psychologist 51: 164-187. https://doi.org/10.1080/00461520. 2016.1155458.

Baas, M., W. Admiraal, and E. van den Berg. 2019. Teachers' adoption of open educational resources in higher education. Journal of Interactive Media in Education, 9. http://doi.org/10.5334/jim e. 510 .

Baker, M.J. 2015. Collaboration in collaborative learning. Interaction Studies 16: 451-473. https:// doi.org/10.1075/is.16.3.05bak.

Bandura, A. (1977). Social learning theory. Englewood Cliffs, NJ: Prentice Hall.

Chinn, C.A., and D.B. Clark. 2013. Learning through collaborative argumentation. In The international handbook of collaborative learning, ed. C.E. Hmelo-Silver, C.A. Chinn, C.K.K. Chan, and A.M. O'Donnell, 314-332. New York: Taylor \& Francis.

Choi, D.S.-Y., and P. Morrison. 2014. Learning to get it right: Understanding change processes in professional development for teachers of English learners. Professional Development in Education 40: 416-435. https://doi.org/10.1080/19415257.2013.806948.

Cox, M. D. 2004. Introduction to faculty learning communities. New directions for teaching and learning, 5-23. https://doi.org/10.1002/tl.129. 
Cuthell, J.P. 2005. What does it take to be active? Teacher participation in online communities. International Journal of Web Based Communities 1: 320-332. https://doi.org/10.1504/IJWBC. 2005.006930.

Danielowich, R.M. 2012. Other teachers' teaching: Understanding the roles of peer group collaboration in teacher reflection and learning. The Teacher Educator 47: 101-122. https://doi.org/10. 1080/08878730.2012.660373.

De Laat, M. F., and B. Schreurs. 2013. Visualizing informal professional development networks: Building a case for learning analytics in the workplace. American Behavioral Scientist. https:// doi.org/10.1177/0002764213479364.

Felton, M., A. Crowell, and T. Liu. 2015. Arguing to agree: Mitigating my-side bias through consensus-seeking dialogue. Written Communication 32: 317-331. https://doi.org/10.1177/074 1088315590788.

Hawkes, M., and A. Romiszowski. 2001. Examining the reflective outcomes of asynchronous computer-mediated communication on inservice teacher development. Journal of Technology and Teacher Education 9: 285-308. https://www.learntechlib.org/primary/p/8425/. Accessed June 17 2020.

Hur, J.W., and T.A. Brush. 2009. Teacher participation in online communities. Journal of Research on Technology in Education 41: 279-303. https://doi.org/10.1080/15391523.2009.10782532.

Inel Ekici, D. 2018. Development of pre-service teachers' teaching self-efficacy beliefs through an online community of practice. Asia Pacific Education Review 19: 27-40. https://doi.org/10.1007/ s12564-017-9511-8.

Kastens, K.A., and C.A. Manduca. 2017. Using systems thinking in the design, Implementation, and evaluation of complex educational innovations, with examples from the integrate project. Journal of Geoscience Education 65: 219-230. https://doi.org/10.5408/16-225.1.

Knowles, M., E. Holton, and R. Swanson. 1998. The adult learner: The definitive classic in adult education and human resource development. Houston: Gulf Publishing.

Kraut, R.E., and P. Resnick. 2011. Building successful online communities: Evidence-based social design. Cambridge: MIT Press.

Kyndt, E., D. Gijbels, I. Grosemans, and V. Donche. 2016. Teachers' everyday professional development: Mapping informal learning activities, antecedents, and learning outcomes. Review of educational research. Advance online publication. https://doi.org/10.3102/0034654315627864.

Lantz-Andersson, A., M. Lundin, and N. Selwyn. 2018. Twenty years of online teacher communities: A systematic review of formally-organized and informally-developed professional learning groups. Teaching and Teacher Education 75: 302-315. https://doi.org/10.1016/j.tate.2018. 07.008 .

Lave, J., and E. Wenger. 1991. Situated learning: Legitimate peripheral participation. Cambridge: Cambridge University Press.

Lin, N. 1999. Building a network theory of social capital. Connections 22: 28-51. http://faculty. washington.edu/matsueda/courses/590/Readings/Lin\%20Network\%20Theory\%201999.pdf. Accessed June 172020.

Loving, C.C., C. Schroeder, R. Kang, C. Shimek, and B. Herbert. 2007. Blogs: Enhancing links in a professional learning community of science and mathematics teachers. Contemporary Issues in Technology and Teacher Education 7: 178-198.

Macià, M., and I. García. 2016. Informal online communities and networks as a source of teacher professional development: A review. Teaching and Teacher Education 55: 291-307. https://doi. org/10.1016/j.tate.2016.01.021.

Mayweg-Paus, E., M. Thiebach, and R. Jucks. 2016. Let me critically question this!-Insights from a training study on the role of questioning on argumentative discourse. International Journal of Educational Research 79: 195-210. https://doi.org/10.1016/j.ijer.2016.05.017.

McKellar, K., K.B. Pitzul, J.Y. Yi, and D.C. Cole. 2014. Evaluating communities of practice and knowledge networks: A systematic scoping review of evaluation frameworks. EcoHealth 11: 383-399. https://doi.org/10.1007/s10393-014-0958-3. 
Namdar, B. 2017. Preservice science teachers' collaborative knowledge building through argumentation on healthy eating in a computer supported collaborative learning environment. The Turkish Online Journal of Educational Technology 16: 132-146. https://www.learntechlib.org/p/189616/. Accessed June 172020.

Noroozi, O., A. Weinberger, H.J. Biemans, M. Mulder, and M. Chizar. 2012. Argumentationbased computer supported collaborative learning (ABCSCL). A synthesis of 15 years of research. Educational Research Review 7: 79-106. https://doi.org/10.1016/j.edurev.2011.11.006.

Prestridge, S. 2019. Categorising teachers' use of social media for their professional learning: A self-generating professional learning paradigm. Computers \& Education 129: 143-158. https:// doi.org/10.1016/j.compedu.2018.11.003.

Stuckey, B. 2004. Making the most of the good advice: Meta-analysis of guidelines for establishing an Internet-Mediated Community of Practice. In Web based communities: Proceedings of the IADIS international conference, ed. P. Kommers and P. Goikoetxea, 4-26. Lisbon, Portugal.

Stuckey, B., and J. D. Smith. 2004. Sustaining communities of practice. In Web based communities: Proceedings of the IADIS international conference, ed. P. Kommers and P. Goikoetxea, 4-26. Lisbon, Portugal.

Trust, T. 2015. Deconstructing an online community of practice: Teachers' actions in the Edmodo math subject community. Journal of Digital Learning in Teacher Education 31: 73-81. https:// doi.org/10.1080/21532974.2015.1011293.

Tseng, F.-C., and F.-Y. Kuo. 2014. A study of social participation and knowledge sharing in the teachers' online professional community of practice. Computers \& Education 72: 37-47. https:// doi.org/10.1016/j.compedu.2013.10.005.

UNESCO. 2002. Forum on the impact of open courseware for higher education in developing countries: final report. http://unesdoc.unesco.org/images/0012/001285/128515e.pdf.

Unwin, A. 2015. Developing new teacher inquiry and criticality: The role of online discussions. British Journal of Educational Technology 46: 1214-1222. https://doi.org/10.1111/bjet.12194.

Vavasseur, C.B., and S.K. MacGregor. 2008. Extending content-focused professional development through online communities of practice. Journal of Research on Technology in Education 40: 517-536. https://doi.org/10.1080/15391523.2008.10782519.

Veerman, A., J. Andriessen, and G. Kanselaar. 2002. Collaborative argumentation in academic education. Instructional Science 30: 155-186. https://doi.org/10.1023/A:1015100631027.

Vogel, F., I. Kollar, S. Ufer, E. Reichersdorfer, K. Reiss, and F. Fischer. 2016. Developing argumentation skills in mathematics through computer-supported collaborative learning: The role of transactivity. Instructional Science 44: 477-500. https://doi.org/10.1007/s11251-016-9380-2.

Weinberger, A., and F. Fischer. 2006. A framework to analyze argumentative knowledge construction in computer-supported collaborative learning. Computers \& Education 46: 71-95. https:// doi.org/10.1016/j.compedu.2005.04.003.

Wenger, E. 1998. Communities of practice: Learning, meaning and identity. New York: Cambridge University.

Wenger, E. 2002. Cultivating communities of practice: A guide to managing knowledge. Boston, MA: Harvard University Press.

Wenger, E. 2012. Communities of practice and social learning systems: The career of a concept. http://wenger-trayner.com/resources/publications/cops-and-learning-systems/. Accessed 30 August 2015.

Wenger, E., B. Trayner, and M. de Laat. 2011. Promoting and assessing value creation in communities and networks: A conceptual framework. Netherlands Ruud de Moor Center Rapport.

Williams, D. 2006. On and off the net: Scales for social capital in an online era. Journal of ComputerMediated Communication 11. https://doi.org/10.1111/j.1083-6101.2006.00029.x.

Elisabeth Mayweg-Paus is Junior Professor for Digital Knowledge Management in Higher Education at the Humboldt University of Berlin and at the Einstein Centre Digital Future since 
2018. Her research interests are in the field of collaborative learning, digital communication and the development of digital skills in formal and informal education.

Maria Zimmermann is a Postdoctoral Researcher at the Humboldt University of Berlin and teaches pre-service teachers since 2014. In her research she is interested in how to promote learning in online learning environments and focuses on the potential of collaborative communication among learners and teachers to acquire the so-called digital skills.

Open Access This chapter is licensed under the terms of the Creative Commons Attribution 4.0 International License (http://creativecommons.org/licenses/by/4.0/), which permits use, sharing, adaptation, distribution and reproduction in any medium or format, as long as you give appropriate credit to the original author(s) and the source, provide a link to the Creative Commons license and indicate if changes were made.

The images or other third party material in this chapter are included in the chapter's Creative Commons license, unless indicated otherwise in a credit line to the material. If material is not included in the chapter's Creative Commons license and your intended use is not permitted by statutory regulation or exceeds the permitted use, you will need to obtain permission directly from the copyright holder. 